\title{
Biochemical Biomarkers-Independent Predictors of Type 2 Diabetes Mellitus
}

\author{
Alice JayaPradha Cheekurthy ${ }^{1 *}$, C Rambabu ${ }^{1}$ and Amit Kumar ${ }^{2}$ \\ ${ }^{1}$ Department of Biochemistry, Acharya Nagarjuna University, India \\ ${ }^{2}$ Acharya Nagarjuna University, 2 CEO, Bio-axis DNA Research Centre, India
}

\begin{abstract}
Biological markers or biomarkers are the indicators of a particular biological state before the appearance of manifestations in form of a disease. A variety of blood biomarkers represent pathology of diabetes. Analysis of blood is an important technique for determining physiological and pathological condition. People suffering from Type 2 diabetes mellitus (T2DM) were part of the study. The people with bleeding disorders and those suffering from other diseases were not included in the study. There were more female $(F)$ diabetic patients than male $(M)$ patients. This case control observational study is an attempt to interpret data obtained from biochemical investigation of diagnostic biochemical parameters of complete blood count and lipid profile for their pathological implication and in prediction risk of Type 2 diabetes mellitus and related complications among the healthy subjects. Normality test was done to check for normal distribution of the data among females (1) and males (2) and the correlation test showed no significant relation of the of biochemical parameters with PBSS.
\end{abstract}

Keywords: Biological markers; Type 2 diabetes mellitus

Abbreviations: FBS: Fasting Blood Sugar; PPBS: Post Prandial Blood Sugar; TC: Total Cholesterol; HDL: High Density Lipoproteins; LDL: Low Density Lipoproteins and TG: Triglycerides; CHD: Coronary Heart Disease

\section{Introduction}

\section{Biomarkers}

"Biomarker or biological marker origin is the characteristic that is objectively measured and evaluated as an indicator of the normal biological processes, pathogenic processes, or pharmacological responses to a therapeutic intervention" (NIH Definition 2001).

Biomarkers provide a dynamic and powerful approach to understand the spectrum of diseases. Candidate biomarkers of health and disease discovery is the result of genome or proteome-wide search. From antibodies which are the simplest biomarkers to the widespread accurate genomics-based biomarkers has shown notable success. Biomarkers for T2 DM are able to answer the questions that move in our minds

- Am I going to get diabetes?

- Have I got diabetes?

- What is the effect of diabetes?

The biomarkers are risk factors that could be of either genetic or non-genetic origin. Among the non-genetic biomarkers the biochemical biomarkers are the independent predictors of Type 2 diabetes.

\section{Type II diabetes mellitus}

Complex interaction between biochemical, environmental and genetic factors can unmask T2DM [1] by predicting its outcome. It is known from ancient times and is designated as disease of affluence [2] and overfed, middle aged and elderly people but now the prevalence of diabetes for all age-groups is worldwide $[3,4]$. The overall burden on family and economy of nation is increasing worldwide as the prevalence of diabetes is increasing continuously at an alarming rate with T2DM accounting for $>90 \%$ of all the cases of diabetes [5] There is an increased incidence and prevalence in both the western world and in the developing countries. About 382 million people worldwide are affected by diabetes and the count will be raised to 529 million by 2035 (International Diabetes Federation estimation). By the end of the century it is estimated to reach indefinite proportions in every country and subsequently it has turned out to be a pandemic.

Diabetes mellitus is a multifaceted group of metabolic diseases characterized by the accumulation of sugar in the blood (hyperglycemia). This condition is due to non utilization of glucose by body cells due to insulin resistance shown by the cells [6,7] or due to insulin deficiency [8]. This results in abnormalities in carbohydrates, protein and fat metabolism [9]. The associated pathogenic processes are involved in the development of diabetes with a long-term damage dysfunction, and failure of various organs especially affecting the eyes, kidneys, nerves, heart, and blood vessels (American Diabetes Association). On entry of nutrients into the blood stream insulin brings down the blood glucose levels by decreasing the exogenous glucose production and stimulation of glucose transport [10]. Patients with long duration of type II diabetes and poor glycemic control have a significantly increased risk of developing related complications making it the most significant global health problems faced today [11-14]. The highest burden is borne by the South East Asian countries [15]. The Indians are more prone to diabetes whether they may be residing in India or outside due to the peculiar characteristics $[16,17]$. Prevalence of more among the urban population, now the prevalence is increasing in rural population due to change in socio economic life styles. The economic burden of treating

*Corresponding author: JayaPradha AC, Department of Biochemistry, Acharya Nagarjuna University, Guntur-22510, Andhra Pradesh, India, Tel: 09581771118; E-mail: alicejaya@gmail.com

Received December 08, 2014; Accepted March 30, 2015; Published April 03 2015

Citation: Cheekurthy AJP, Rambabu C, Kumar A (2015) Biochemical BiomarkersIndependent Predictors of Type 2 Diabetes Mellitus. J Bioanal Biomed 7: 035-039. doi:10.4172/1948-593X.1000121

Copyright: ( 2015 Cheekurthy AJP, et al. This is an open-access article distributed under the terms of the Creative Commons Attribution License, which permits unrestricted use, distribution, and reproduction in any medium, provided the original author and source are credited. 
diabetes and its complications is increasing at a fast pace with increase in number of upcoming cases of diabetes.

Complex diseases like diabetes do not have a single cause to occur. Several modifiable risk factors, non-modifiable risk factors of nongenetic origin and of genetic [18] origin have been studied for T2DM and related complications. Previously nationwide [19] and worldwide [20] studies have been carried to find out the importance of investigating the biochemical parameters in blood and lipid profile in advancement and progression of T2DM. These biochemical parameters are the risk factors for the development of T2DM and related complications when tested in controls [21-23]. These risk factors confer the risk validated by the presence of inheritable subset of SNP which do not change throughout one's life and the person could expect their effects in the later stages of life.

\section{Methodology}

This is a part of case control study to find how non-genetic and genetic risk factors together are responsible for outcome of T2DM and related complications in discrete population of Andhra Pradesh and Telangana States of India. This study is an attempt to interpret data obtained from biochemical investigation of diagnostic biochemical parameters of complete blood count and lipid profile along FBS and PPBS levels. Pathological implications of these biochemical parameters and the prediction of T2DM and the related complications are the risk factors among the healthy subjects.

The study is carried out with 180 subjects of which 96 were females (1) and 84 were males (2) (90 subjects (females 54; males 36) are diabetic cases and 90 subjects (females 42 ; males 48 ) are controls. Their left over blood sample was collected after taking their consent. The case subjects of the study were established diabetic patients based on their biochemical reports which showed FBS value of more than $126 \mathrm{mg} /$ $\mathrm{dl}$ or $\geq 7.0 \mathrm{mmol} / \mathrm{L}$ and PPBS value of more than $200 \mathrm{mg} / \mathrm{dl}$ or $\geq 11.1$ $\mathrm{mmol} / \mathrm{L}$ (WHO diagnostic criteria for diabetes). The healthy subjects with no family history of diabetes served as controls. Subjects suffering from other infectious diseases were excluded from the study. They were either motivated or prescribed by the doctor for the screening of diabetes.

\section{Experimental Details}

The Fasting and Postprandial whole blood samples were collected from diabetic patients aged between $15-85$ years and normal subjects from Andhra Pradesh and Telangana States of India. The samples were collected in both EDTA [24] and non-EDTA vacutainers in accordance to the protocol of some of the investigations and not for the purpose of comparison. Blood samples were collected from them after obtaining information related to age, sex, life style and history. Blood samples were collected in sitting position by tying a band to make the vein more prominent. The data of lipid profiles and complete blood count along with the FBS and PPBS was obtained by investigation of the biochemical parameters. Blood sugar levels (FBS, PPBS) estimated by glucose oxidase and peroxidase (GOD-POD) method [25].

Hemoglobin was determined by cyanmethemoglobin method and lipid profiles (TC, HDL, LDL, VLDL, TG ) were analyzed using Star 21 plus auto-analyzer were measured by Kellys end point method, the end point method is so called as the analytes are completely consumed in the reaction. The coloured complex thus formed at the end of reaction period is read for its absorbance using a spectro-photometer. All the chemicals used in this study were of analytical grade.

\section{Biochemical Evaluation}

The Biochemical data and characteristics of the study participants was compared along with the normal reference range for the different Biochemical parameters as shown in the Tables 1 and 2 below. The data for different parameters are presented in the Tables as mean \pm standard deviation. The units of measurement for all the parameters is $\mathrm{mg} / \mathrm{dl}$ and that of different types of WBC and total WBC are expressed as percent (\%) and/cmm and $\mathrm{Hb}$ in grams.

\section{Discussion and Results}

Glucose gets into the cells with the help of a hormone called insulin. T2DM is a condition characterized by hyperglycemic condition due to either insulin resistance and absolute or partial deficiency of insulin secretion by the pancreatic $\beta$-cell. Diabetes is a chronic disorder resulting from imbalance between the insulin sensitivity and the insulin secretion. There is no single cause for diabetes as it is a multifactorial disease.

The study showed that there is an increase in the values of some biochemical parameters investigated in the T2DM cases when compared to the control values but within the normal range. The blood sugar levels were found to be high in both male and female patients as per the WHO diagnostic criteria for diabetes. Poorly controlled PPBS levels have adverse affect on arteries that leads to either microvascular (small vessels) or macrovascular vessels (large) or both complications [26-29]. It independently show association with disability and death caused by cardiovascular disease irrespective of FBS. Occurrence of anaemia in patients with T2DM is a frequent condition [30,31]. Gender specific of investigation of anemia is done in females when the hemoglobin levels are less than $12 \mathrm{~g} / \mathrm{dL}$ and in men when it is less than $13 \mathrm{~g} / \mathrm{dL}$ [32] (WHO recommended criteria). Anaemia is an important predictor for microvascular disease [33] or progression of kidney diseases [34]. Anaemia contributes to tiredness in $74 \%$ of the diabetic people than those without anaemia [35]. The abnormalities of lipid profile or dyslipidemia are associated with the T2DM and it is one of the major risk factors for cardiovascular diseases [36,37]. The elevated levels of triglycerides with low HDL levels when compared to normal ones showed an increased risk of coronary heart disease (CHD) [38].

T2DM has an impact on total and differential counts of WBC [39]. After controlling conventional risk factors WBC count worsens the insulin senstivity [40]. Increased WBC count is independent

\begin{tabular}{|c|c|c|c|c|}
\hline Parameter & $\begin{array}{c}\text { T2DM Cases } \\
\text { Mean } \pm \text { SD }\end{array}$ & $\begin{array}{c}\text { Controls } \\
\text { Mean } \pm \text { SD }\end{array}$ & Normal Range & "P=value \\
\hline FBS & $152 \pm 92.8$ & $92 \pm 11.7$ & $70-110$ & 0.8 \\
\hline PPBS & $229.3 \pm 67.6$ & $131.2 \pm 18.8$ & $170-200$ & 0.7 \\
\hline
\end{tabular}

Table 1: Blood sugar levels.

\begin{tabular}{|c|c|c|c|c|}
\hline Parameter & $\begin{array}{c}\text { T2DM Cases } \\
\text { Mean } \pm \text { SD }\end{array}$ & $\begin{array}{c}\text { Controls } \\
\text { Mean } \pm \text { SD }\end{array}$ & $\begin{array}{c}\text { Normal } \\
\text { Range }\end{array}$ & *P=value \\
\hline Total Cholesterol & $176.8 \pm 50.3$ & $163 \pm 51.7$ & $130-250$ & 0.09 \\
\hline Triglycerides & $198.1 \pm 87.7$ & $141 \pm 56.9$ & $50-150$ & 0.1 \\
\hline HDL & $42.5 \pm 4.7$ & $43.2 \pm 5.9$ & $35-70$ & 0.05 \\
\hline LDL & $86.4 \pm 25.8$ & $44.0 \pm 28.6$ & Upto140 & 0.09 \\
\hline VLDL & $41.8 \pm 20.7$ & $28.6 \pm 13.6$ & $10-40$ & 0.09 \\
\hline Total WBC Count & $8116.6 \pm 1196.3$ & $7785 \pm 1759$ & $4000-11000$ & 0.1 \\
\hline Neutophils & $64.8 \pm 7.4$ & $63.88 \pm 7.2$ & $40-75 \%$ & 0.8 \\
\hline Haemoglobin & $11.9 \pm 1.8$ & $12 \pm 1.2$ & $\begin{array}{c}\mathrm{M}=13.5-18 \mathrm{~g} \\
\mathrm{~F}=12-15 \mathrm{~g}\end{array}$ & 0.2 \\
\hline
\end{tabular}

Table 2: Biochemical characteristics of study participants. 
Citation: Cheekurthy AJP, Rambabu C, Kumar A (2015) Biochemical Biomarkers-Independent Predictors of Type 2 Diabetes Mellitus. J Bioanal Biomed 7: 035-039. doi:10.4172/1948-593X.1000121

\begin{tabular}{|c|c|c|c|c|c|c|}
\hline Parameter & Skewness & Kurtosis & Standard Error(SE) & Skewness & Kurtosis & Standard Error (SE) \\
\hline PPBS & 1.763 & 3.72 & $\pm 0.32 \pm 0.63$ & 1.8 & 4.33 \\
\hline TG & 1.298 & 1.288 & $\pm 0.325 \pm 0.398$ & 1.288 & 0.808 \\
\hline HDL & 418 & -1.448 & $\pm 0.325 \pm 0.639$ & 0.073 & -1.839 \\
\hline LDL & 0.466 & -0.181 & $\pm 0.398 \pm 0.778$ & -0.451 & 0.653 & -1 \\
\hline N/L & 0.878 & 1.927 & $\pm 0.512 \pm 0.992$ & 0.026 & -1.359 \\
\hline
\end{tabular}

Table 3: Skewness and Kurtosis z- values.

\begin{tabular}{|c|c|c|}
\hline Parameter & Males & Females \\
\hline PPBS & 0.00 & 0.00 \\
\hline TG & 0.00 & 0.00 \\
\hline HDL & 0.00 & 0.000 \\
\hline LDL & 0.198 & 0.590 \\
\hline N/L & 0.015 & 0.121 \\
\hline
\end{tabular}

Table 4: Shapiro-Wilk test p-values.

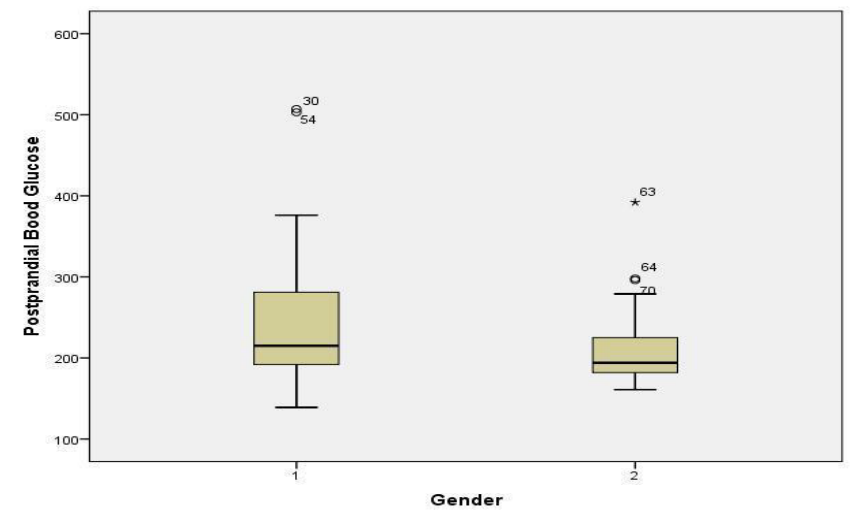

Graph 1: Box plot for distribution of PPBS among females (1) and males (2).

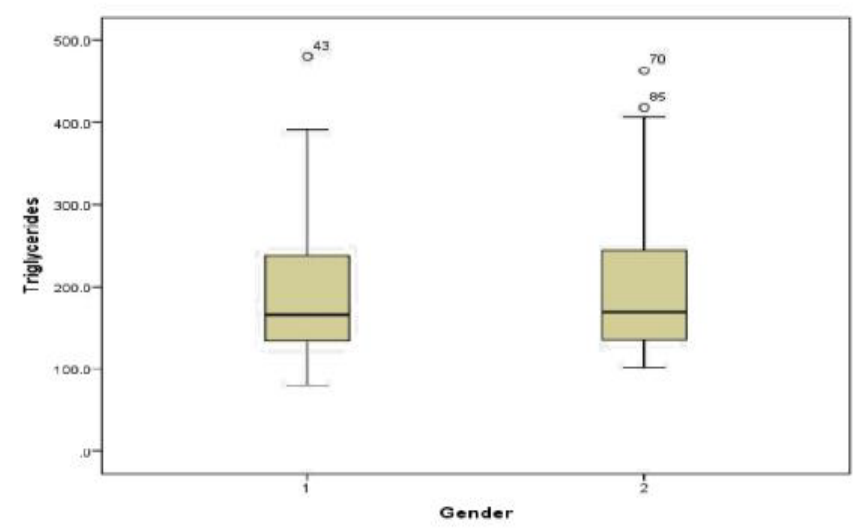

Graph 2: Box plot for distribution of TG among females (1) and males (2).

biomarkers for macro and microvascular complications [41] responsible for death and disability in T2DM patients. Lymphocyte count is decreased with the advancement of diabetic nephropathy even in the normal range [42]. The future incidence of CHD is predicted by the total $[43,44]$ and the differential cell counts of WBC (eosinophils, neutrophils, and monocytes) [45]. NLR (Neutral Lymphocyte Ratio) is an essential marker of systemic inflammation and T2DM and are indicator of increased risk for cardiovascular events in patients [46].

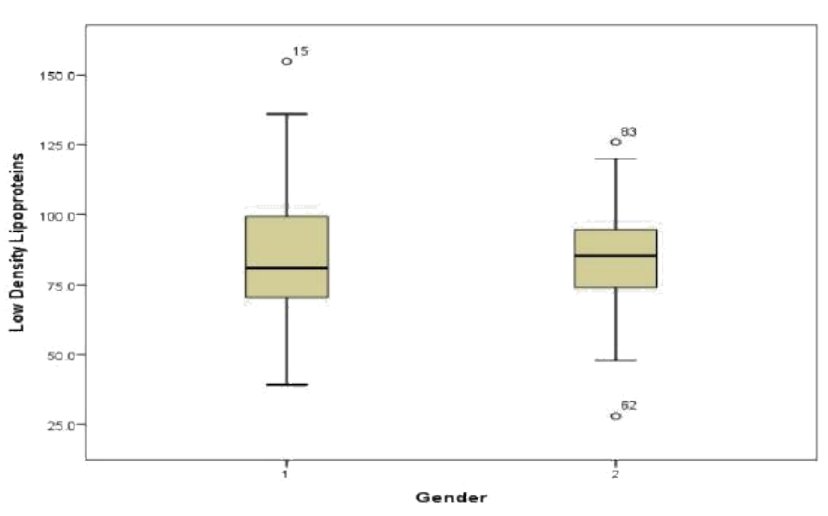

Graph 3: Box plot for distribution of LDL among females (1) and males (2).

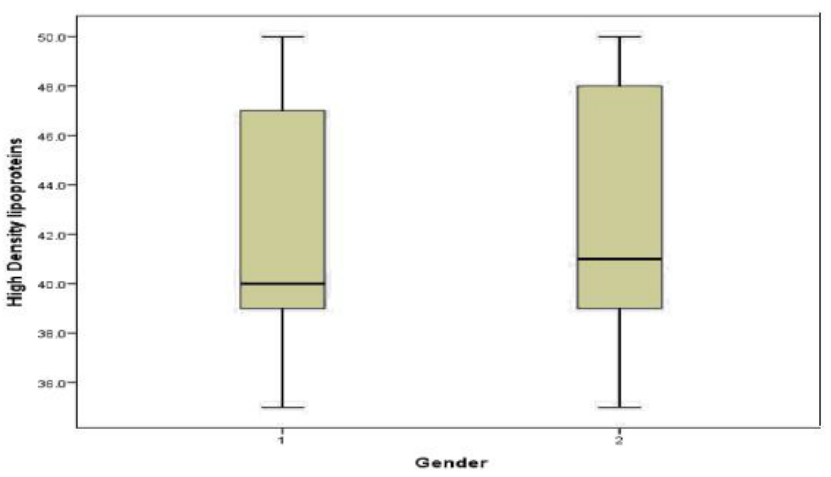

Graph 4: Box plot for distribution of HDL among females (1) and males (2).

\section{Statistical analysis}

The following numerical and visual outputs are investigated with the help of IBM SPSS v.21 Software. Normality test was performed to check whether the post prandial blood sugar levels and other lipid profile values are normally distributed among female (1) and male (2) diabetic patients. The Graph 1 box plot shows that the PPBS were not normally distributed among the males and females. The Graphs 2,3 and 4 box plot shows that the TG, LDL and HDL were not normally distributed among the males and females.

Significant difference was observed between the PBSS scores for female (1) $(\mathrm{M}=24.31, \mathrm{SD}=76.05)$ and male (2) $(\mathrm{M}=211.86, \mathrm{SD}=48.81)$; $\mathrm{t}(87)=2.03, \mathrm{p}=0.045$ on conducting an independent $\mathrm{T}$-test. The observed lipid profile variables were analyzed for correlation by Pearson's correlation test and showed no statistically significant correlation between PBSS vs TG, HDL vs PBSS, LDL vs PBSS. R square values are $0.001,0.002$ and 0.009 for TG, LDL and HDL respectively. The Pearson correlations are shown below in Graphs 5,6 and 7. 


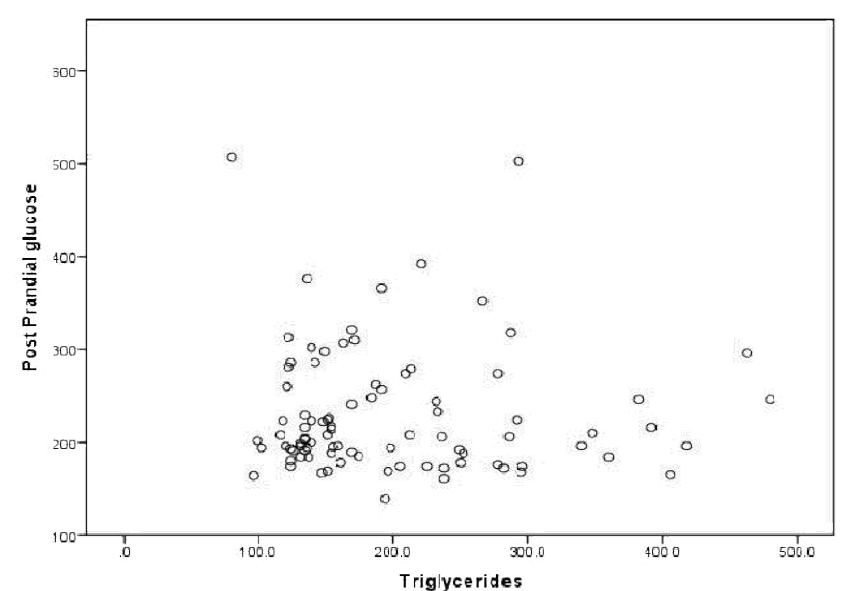

Graph 5: Pearson correlation between PBSS vs TG.

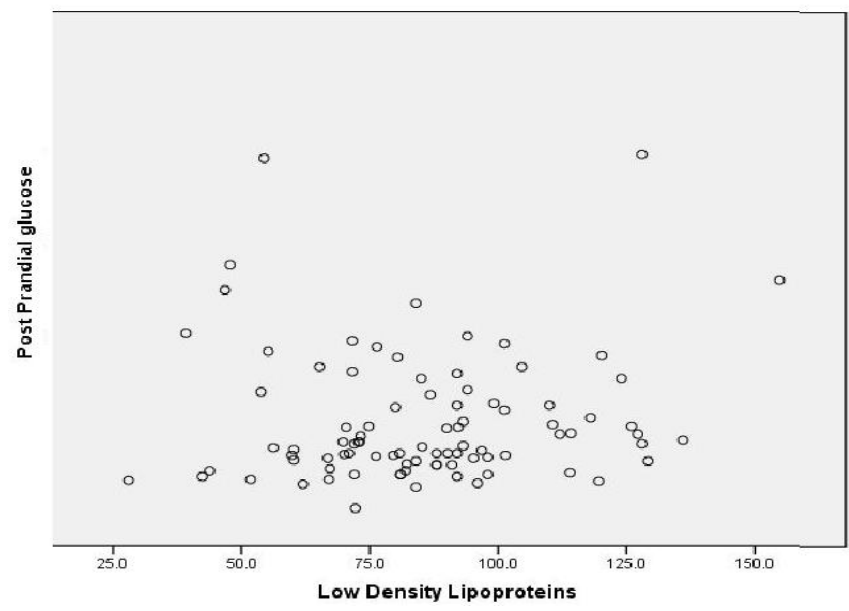

Graph 6: Pearson Correlation between PBSS vs LDL.

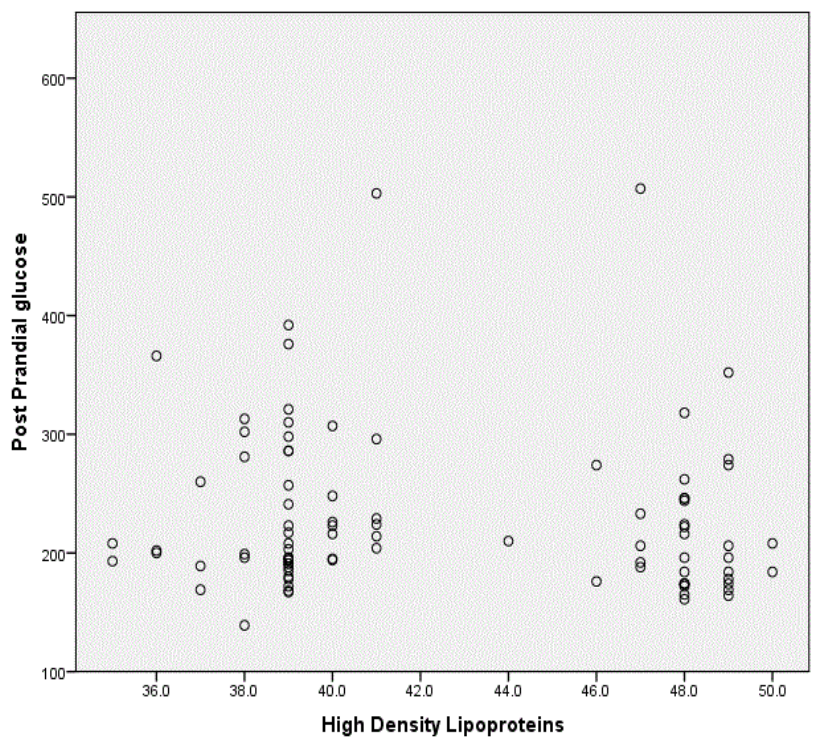

Graph 7: Correlation between HDL vs PBSS.

\section{Conclusion and Future Directions}

Diabetes has no cure but can be kept under control by making small modifications in the life style and it will certainly help to prolong the onset of diabetes and related complications in affected people. The higher levels of cholesterol is one of the risk factors for dyslipidemia in the subjects normal for T2DM. Our further studies had revealed the presence of SNPs for dyslipidemia in controls also. Increased levels of Lipids and decreased HDL along with high post prandial blood sugar will result in cardiovascular complications and will lead mortality and morbidity. Lower levels of hemoglobin cause tiredness and vascular complications. Increased WBC count but within range is an independent biomarker for onset of T2DM decreased of lymphocyte count indicates the advancement diabetic nephropathy. The difference in normality shows the difference in susceptibility of T2DM among female (1) and male (2). There is an urgent need for research to identify other risk factors for predisposition of diabetes. Further, the study is continued to find the genetic and other non genetic factors for predicting the out come of T2DM and related complications.

\section{References}

1. Cheekurthy AJ, Babu CR, Kumar A, Surendrababu K (2015) Predisposition Factors of Type II Diabetes Mellitus and Related Complications. In Biotechnology and Bioforensics pp. 43-50.

2. WHO (2015) Chronic diseases create large adverse - and underappreciated economic effects on families, communities and countries.

3. Sunita Singh (2011) The genetics of type 2 diabetes mellitus: a review. J Sci Res 55: 35-48.

4. Wild S, Roglic G, Green A, Sicree R, King H (2004) Global prevalence of diabetes: estimates for the year 2000 and projections for 2030. Diabetes Care 27: 1047-1053.

5. American Diabetes Association (2010) Diagnosis and Classification of Diabetes Mellitus Diabetes Care 33: S62-S69.

6. O'Doherty R, Stein D, Foley J (1997) Insulin resistance. Diabetologia 40 Supp 3: B10-15.

7. Lillioja S, Mott DM, Spraul M, Ferraro R, Foley JE, et al. (1993) Insulin resistance and insulin secretory dysfunction as precursors of non-insulindependent diabetes mellitus. Prospective studies of Pima Indians. N Engl J Med 329: 1988-1992.

8. Kumar V, Abul KA, Nelson F, Stanley LR, Ramzi SC (2005) Robbins and Cotran Pathologic Basis of Disease. Philadelphia: Elsevier Saunders.

9. Basavanthappa BT (2005) Medical Surgical Nursing. (1st Edition) Jaypee Brothers Medical Publishers pp 687.

10. Coomans CP, Biermasz NR, Geerling JJ, Guigas B, Rensen PC, et al. (2011) Stimulatory affect of glucose uptake by muscles. Diabetes 60: 3132-3140.

11. Basit A, Hydrie MZI, Hakeem R, Ahmedani MY, Waseem M (2014) Glycemic control, hypertension and chronic complications in type 2 diabetic subjects attending a tertiary care center. J Ayub Med Coll Abbottabad 17: 63-68.

12. Ramachandran A, Snehalatha C, Satyavani K, Latha E, Sasikala R, et al. (1999) Prevalence of vascular complications and their risk factors in type 2 diabetes. J Assoc Physicians India 47: 1152-1156.

13. Agrawal RP, Ranka M, Beniwal R, Sharma S, Purohit VP, et al. (2004). Prevalence of micro and macro vascular complications in type 2 diabetes and their riskfactors. Age 50: 12-14.

14. Shera AS, Jawad F, Maqsood A, Jamal S, Azfar M, et al. (2004) Prevalence of chronic complications and associated factors in type 2 diabetes. J Pak Med Assoc 54: 54-59.

15. Litwak L, Goh SY, Hussein Z, Malek R, Prusty V, et al. (2013) Prevalence of diabetes complications in people with type 2 diabetes mellitus and its association with baseline characteristics in the multinational A1chieve study. Diabetol Metab Syndr 5: 57.

16. World Health Organization (2002) Health situation in the South-East Asia region 1998-2000. SEA/HS/222, WHO Regional Office for South-East Asia, New Delhi. 
Citation: Cheekurthy AJP, Rambabu C, Kumar A (2015) Biochemical Biomarkers-Independent Predictors of Type 2 Diabetes Mellitus. J Bioanal Biomed 7: 035-039. doi:10.4172/1948-593X.1000121

17. World Diabetes Foundation (2003) International Diabetes Federation. Diabetes Atlas for 2003 pp 2

18. Talmud PJ, Hingorani AD, Cooper JA, Marmot MG, Brunner EJ, et al. (2010) Utility of genetic and non-genetic risk factors in prediction of type 2 diabetes: Whitehall II prospective cohort study. BMJ 340: b4838.

19. Ramachandran AD (2007) Insulin resistance among Asian-Indian adolescents, Diabetes Care 30

20. Gordon L, Ragoobirsingh D, Morrison EY, Choo-Kang E, McGrowder D, et al. (2010) Lipid profile of type 2 diabetic and hypertensive patients in the jamaican population. J Lab Physicians 2: 25-30.

21. Yadav R, Tiwari P, Dhanaraj E (2008) Risk factors and complications of type 2 diabetes in Asians. CRIPS 9: 8-12.

22. Prabhu S (2013) Genetic and Biochemical risk factors for type 2 diabetes mellitus. Indian Journal of Biotechnology 12: 447-450.

23. Sattar N, Wannamethee SG, Forouhi NG (2008) Novel biochemical risk factors for type 2 diabetes: pathogenic insights or prediction possibilities? Diabetologia 51: $926-940$

24. Banfi G, Salvagno GL, Lippi G (2007) The role of ethylenediamine tetraacetic acid (EDTA) as in vitro anticoagulant for diagnostic purposes. Clin Chem Lab Med 45: 565-576.

25. Huggett AS, Nixon DA (1957) Use of glucose oxidase, peroxidase, and O-dianisidine in determination of blood and urinary glucose. Lancet 273: 368-370.

26. Home P (2005) Contributions of basal and post-prandial hyperglycaemia to micro- and macrovascular complications in people with type 2 diabetes. Curr Med Res Opin 21: 989-998.

27. Bonora E (2002) Postprandial peaks as a risk factor for cardiovascular disease: epidemiological perspectives. Int J Clin Pract Suppl: 5-11.

28. Hanefeld M (2002) Postprandial hyperglycaemia: noxious effects on the vesse wall. International journal of clinical practice. Supplement 45-50.

29. Heine RJ, Balkau B, Ceriello A, Del Prato S, Horton ES, et al. (2004) What does postprandial hyperglycaemia mean? Diabet Med 21: 208-213.

30. Ranil PK, Raman R, Rachepalli SR, Pal SS, Kulothungan V, et al. (2010) Anemia and diabetic retinopathy in type 2 diabetes mellitus. J Assoc Physicians India 58: 91-94.

31. Thomas MC, Maclsaac RJ, Tsalamandris C, Power D, Jerums G (2003) Unrecognized anemia in patients with diabetes: a cross-sectional survey. Diabetes Care 26: 1164-1169.

32. (1968) Nutritional anaemias. Report of a WHO scientific group. World Health Organ Tech Rep Ser 405: 5-37.

33. Thomas MC (2007) Anemia in diabetes: marker or mediator of microvascular disease? Nat Clin Pract Nephrol 3: 20-30.

34. Mehdi U, Toto RD (2009) Anemia, diabetes, and chronic kidney disease. Diabetes Care 32: 1320-1326.
35. Stevens PE, O'Donoghue DJ, Lameire NR (2003) Anaemia in patients with diabetes: unrecognised, undetected and untreated? Curr Med Res Opin 19 395-401.

36. Mooradian AD (2009) Dyslipidemia in type 2 diabetes mellitus. Nat Clin Pract Endocrinol Metab 5: 150-159.

37. Arun K, Ramiah S (2008) Serum lipid profile abnormality in predicting the risk of myocardial infarction in elderly normolipidaemic patients in South Asia: a casecontrolled study. The Internet Journal of Alternative Medicine 6.

38. Krauss RM (2004) Lipids and lipoproteins in patients with type 2 diabetes Diabetes Care 27: 1496-1504.

39. Zaidan HK, Ibrahim IH, Al Saadi AH, Ewadh MJ, Al Ameri QMA (2012) Tota and differential leukocytes count in type 2 diabetes mellitus patients in Iraq. Research in Biotechnology 3.

40. Vozarova B, Weyer C, Lindsay RS, Pratley RE, Bogardus C, et al. (2002) High white blood cell count is associated with a worsening of insulin sensitivity and predicts the development of type 2 diabetes. Diabetes 51: 455-461.

41. Tong PC, Lee KF, So WY, Ng MH, Chan WB, et al. (2004) White blood cell count is associated with macro- and microvascular complications in chinese patients with type 2 diabetes. Diabetes Care 27: 216-222.

42. Chung FM, Tsai JC, Chang DM, Shin SJ, Lee YJ (2005) Peripheral total and differential leukocyte count in diabetic nephropathy: the relationship of plasma leptin to leukocytosis. Diabetes Care 28: 1710-1717.

43. Madjid M, Awan I, Willerson JT, Casscells SW (2004) Leukocyte count and coronary heart disease: implications for risk assessment. J Am Coll Cardiol 44: 1945-1956.

44. Prentice RL, Szatrowski TP, Fujikura T, Kato H, Mason MW, et al. (1982) Leukocyte counts and coronary heart disease in a Japanese cohort. Am J Epidemiol 116: 496-509.

45. Olivares R, Ducimetière $P$, Claude JR (1993) Monocyte count: a risk factor for coronary heart disease? Am J Epidemiol 137: 49-53.

46. Shiny A, Bibin YS, Shanthirani CS, Regin BS, Anjana RM, et al. (2014) Association of neutrophil-lymphocyte ratio with glucose intolerance: an indicator of systemic inflammation in patients with type 2 diabetes. Diabetes technology and therapeutics 16: 524-530. 